\title{
Standardization of zygotic embryo culture from Nerium oleander L. and comparative analysis of biosynthesized cardiac glycosides within in vitro and acclimatized plants
}

\author{
Renu Nimoriya', Yatendra Singh', Sumit Kumar Singh",2, Pankaj Singh', \\ Amar Jeet', Carol Janis Bilung',2, Sanjeev Kanojiya, ${ }^{1,2}$, Dipak Kumar Mishra,2* \\ 'Sophisticated Analytical Instrument Facility \& Research, CSIR-Central Drug Research Institute, Sector 10, Jankipuram \\ Extension, Sitapur Road, Lucknow-226031, Uttar Pradesh, India, ${ }^{2}$ Academy of Scientific and Innovative Research \\ (AcSIR), Ghaziabad-201002, Uttar Pradesh, India
}

\begin{abstract}
The primary result of our experiment revealed that the germination percentage of N. oleander mature seeds is only $30 \%$. From this observation, the concept of protocol standardization for zygotic embryo culture of this plant was originated. Zygotic embryo culture was proved an efficient in vitro multiplication system of $\mathrm{N}$. oleander. The maximum germination percentage (96\%) of zygotic embryos was observed on $1 / 4$ MS medium with $15 \mathrm{gm} / \mathrm{L}$ sucrose, whereas the best growth medium was optimized as $1 / 2$ B 5 with same sucrose concentration. The second part of this study was aimed to find out the cardiac glycoside accumulation pattern in both in vitro and acclimatized plants. For this purpose, one-month-old in vitro plantlets and acclimatized plants were subjected to LC-MS analysis and 09 cardiac glycosides were detected and quantified in both systems. Most of the cardiac glycosides including odoroside A $(32.71 \mathrm{mg} / \mathrm{gm} \mathrm{DW})$, odoroside $\mathrm{H}$ $(4.69 \mathrm{mg} / \mathrm{gm} \mathrm{DW})$ and oleandrin $(0.52 \mathrm{mg} / \mathrm{gm} \mathrm{DW})$ were found to be accumulated at the maximum level within in vitro plantlets. CG 840b $(1.89 \mathrm{mg} / \mathrm{gm}$ DW) is the only cardiac glycoside, which was maximally accumulated in acclimatized plants. From this study, it can be concluded that zygotic embryo culture is a better choice for in vitro multiplication of N. oleander when compared to matured seeds and in vitro grown plantlets of this species favor cardiac glycosides biosynthesis in comparison to acclimatized plants. Therefore, all future research on the enrichment of cardiac glycosides from this plant may be conducted on zygotic embryos derived in vitro grown plantlets or cultures.
\end{abstract}

Revised: September 02, 2021

Accepted: September 02, 2021 Published: December 28, 2021

*Corresponding author:

Dipak Kumar Mishra

E-mail: dk_mishra@cdri.res.in
KEYWORDS: Nerium oleander, Cardiac glycoside quantification, Zygotic embryo culture, Acclimatized plants, UPLC-MS/MS analysis

\section{INTRODUCTION}

Zygotic embryo culture (ZEC), first introduced by Henning in 1906, has proven its outstanding efficiency in expanding the plant population on a laboratory scale. In vitro Plantlets (IVP), developed through ZEC under controlled culture conditions, can provide sterile starting materials (explants) for experimental purposes without much metabolic alteration. Such plantlets can also be efficiently used for the biosynthesis and enrichment of targeted bioactive metabolites (Grosser \& Collins, 1984; Bridgen, 1994; Haslam \& Yeung, 2011). However, the embryo's delicate nature requires an exact medium composition to support its germination and increased plantlet survival. On the other hand, plantlet production from mature wild-type seeds is sometimes very complicated and time-consuming due to the slow germination rate (Ramming, 2019).

Nerium oleander, a member of the family Apocynaceae, typically characterized by the presence of latex is an evergreen shrub or small tree. It is highly enriched with various classes of compounds like pragnanes, terpenoids, phenolics, tannins, chlorogenic acids, alkaloids and cardiac glycosides (CGs) (Ekalu et al., 2019). CGs are medicinally useful as cardiotonic (Matsui \& Schwartz, 1968), anti-proliferative, immunomodulatory, CNS depressant, anti-inflammatory and antiviral agent (Matsui \& Schwartz, 1968; Newman et al., 2008;

Copyright: (C) The authors. This article is open access and licensed under the terms of the Creative Commons Attribution License (http://creativecommons.org/licenses/by/4.0/) which permits unrestricted, use, distribution and reproduction in any medium, or format for any purpose, even commercially provided the work is properly cited. Attribution - You must give appropriate credit, provide a link to the license, and indicate if changes were made. 
Menger et al., 2013; Dogar et al., 2020; Plante et al., 2020; Tiwari et al., 2020). CGs are the principal active constituent of Anvirzel and PBI-02504, the aqueous and supercritical $\mathrm{CO}_{2}$ extracts of $N$. oleander respectively. Both have been submitted for phase II clinical trial due to their high potency against various types of cancer, including pancreatic and glioma (Wang et al., 2000; Mekhail et al., 2006; Colapietro et al., 2020). Structurally, CGs have steroidal moiety attached with sucrose and are well known for the activity against $\mathrm{Na}^{+}-\mathrm{K}^{+}$ ATPase pump to produce an inhibitory effect. CGs have also been reported to involve complex cell-signal transduction mechanisms, resulting in selective control of tumors without affecting normal cell growth and division (Newman et al., 2008). Numerous in vitro and in vivo studies support the antiproliferative and apoptotic effects of CGs from N. oleander in several cancer cell lines, including breast, prostate, lung, leukemia, melanoma, pancreatic, neuroblastoma and renal adenocarcinoma. Recent studies have also shown the activity of Nerium's CGs against retroviruses like HIV and SARS COVID-19 (Reddy et al., 2020).

However, the main drawback of performing drug development research on this class of compounds is their overall concentration within the plant, which is abysmally low. Moreover, the accumulation of these metabolites fluctuates with the plant growth stage, season and tissue type. Hence, there is a need to establish in vitro cultures of $N$. oleander for constant and higher production of targeted metabolites. Although, a few reports on oleandrin biosynthesis in suspension culture have been published (Ibrahim et al., 2009a, 2009b) but significant enrichment of other CGs like odoroside H, odoroside A is yet to be achieved. In vitro culture is a well-known practice for a steady and higher accumulation of various essential metabolites under different classes. In particular, concerning the large-scale biosynthesis of CGs, the organ and whole plant cultures are considered as a better option than the callus and suspension cultures (Isah et al., 2018; P. Singh et al., 2019). This could be explained by the fact that organ and whole plant cultures are developmentally well-regulated like the shoot, leaf, root, etc. as compared to the undifferentiated cultures like callus or suspension (Hagimori et al., 1982; Zhang et al., 2011). The present study is a first-time report on developing a standardized protocol for rapid multiplication of $N$. oleander through ZEC and the subsequent identification and quantification of their CGs content. For the first time, a total of 09 CGs including the bioactive odoroside $\mathrm{A}\left(\mathrm{C}_{30} \mathrm{H}_{47} \mathrm{O}_{7}\right)$, odoroside $\mathrm{H}\left(\mathrm{C}_{30} \mathrm{H}_{46} \mathrm{O}_{8}\right)$, oleandrin $\left(\mathrm{C}_{32} \mathrm{H}_{49} \mathrm{O}_{9}\right)$, and others were biosynthesized in the in vitro model. A comparative analysis of accumulated CGs within IVP and acclimatized plants (ACP) was also made.

\section{MATERIAL AND METHODS}

Murashige and Skoog medium (MS), Schenk and Hiderbrant medium (SHM), Woody plant medium (WPM), Gamborg B5 medium (B5), sucrose, cetrimide, agar and $\mathrm{NaOH}$ were purchased from Hi-Media Laboratories (Mumbai, India). Extran detergent and HPLC grade methanol were procured from Merck Specialties (Mumbai, India). $\mathrm{HCl}$ was supplied by Ranken RFCL Ltd. (New Delhi, India) and absolute ethanol (HPLC grade) was acquired from Fisher chemical. Phytochemical standards like oleandrin, odoroside A and odoroside $\mathrm{H}$ were purchased from Wuhan Chem Faces Biochemical Co. Ltd., Hubei, PRC. The undehisced pods were collected freshly from healthy and actively growing fully mature plants, located at Jankipuram Extension, Lucknow during the fruiting period (September-January 2020) (FigurelA \& B). The seeds of the same plant were used as starting material for ZEC. Simultaneously, the mature seeds from the same plant were also collected to know their germination vigor under in vitro conditions. Plant authentication was done by the corresponding author of this paper and voucher specimen No. 25294 was deposited at CSIR-CDRI Herbarium.

\section{Explant Preparation for ZEC}

Fruits were washed thoroughly under running tap water for 30 minutes and then treated with a $10 \%$ aqueous solution of extran (detergent) with gentle stirring. After 20 minutes, explants were transferred under running tap water to remove all traces of soap. These clean, dirt-free explants were dipped in $3 \% \mathrm{w} / \mathrm{v}$ cetrimide (aq) for 10 minutes to get rid of any unwanted microbial load and then washed thoroughly by double distilled water (DDW). Further steps were done under a laminar airflow hood, where the pods were treated with $0.2 \% \mathrm{w} / \mathrm{v} \mathrm{HgCl}_{2}$ for 2 minutes with continuous shaking, followed by 3-5 times rinsing with sterile DDW. After surface sterilization, the pods were opened with a sterilized scalpel under aseptic conditions. The fresh immature seeds were dissected out carefully, followed by the isolation of zygotic embryos and their incubation in a culture media plate (twenty per plate). After germination, the plantlets were transferred into culture bottles containing different media with variable salt strength and sucrose concentrations.

\section{Optimization of ZEC}

To investigate the effect of media, zygotic embryos were cultured on one fourth (1/4), half (1/2) and full-strength MS (Murashige \& Skoog, 1962), WPM (McCown, 1981), SHM (Schenk \& Hildebrandt, 1972) and B5 (Gamborg et al., 1968) media, each with three levels of sucrose $(0,15$ and $30 \mathrm{~g} /)$. All the media were solidified with $0.8 \%(\mathrm{w} / \mathrm{v})$ agar (Bacteriological grade). The $\mathrm{pH}$ of all media was adjusted to 5.8 and autoclaved for $20 \mathrm{~min}$ at $121^{\circ} \mathrm{C}$ and $15 \mathrm{psi}$. Isolated embryos were placed horizontally on the medium in culture plates, which were maintained at $25 \pm 2^{\circ} \mathrm{C}$ in the dark for germination and then transferred to $16 / 8 \mathrm{~h}$ of dark/light photoperiod after one week. (Figure l C). Before the optimization of culture media for ZEC, efforts were made to know the germination percentage of mature seeds from the wild plants under in vitro condition.

\section{Plant Acclimatization}

The 4-week-old in vitro germinated plantlets were recovered from the culture bottles and washed gently with sterile DDW to remove all the media traces and then transferred to plastic pots containing soilrite: vermiculite $(1: 1)$. Pots were covered with 
plastic bags and maintained under controlled environmental conditions. After four weeks, plants were transferred to earthen pots containing garden soil and kept in normal daylight conditions in the partially shaded field. Each experiment set was repeated thrice (Figure 1D-G).

\section{Harvesting and Sample Preparation for CGs Profiling}

Four-week-old IVP, grown under different culture media and the ACP were washed and dried in a traditional hot air oven at $40^{\circ} \mathrm{C}$. Samples were then finely ground and $50 \mathrm{mg}$ of each sample was extracted with $5 \mathrm{ml}$ of HPLC grade methanol for 72 hrs. The supernatant was filtered out and passed through a $0.2 \mu \mathrm{m}$ membrane filter (Millex-GV, PVDF, Merck Millipore, Darmstadt, Germany) and $1 \mathrm{ml}$ of each extract was submitted for LC-MS analysis.

\section{Qualitative Analysis of CGs}

Qualitative analysis of the CGs was done using (UPLCMS/ MS) ultra-performance liquid chromatography with electrospray ionization-triple quadruple mass spectrometer (Waters USA) system. For analysis, Waters BEH C18 (100 $\times 2.1 \mathrm{~mm}, 1.7 \mu \mathrm{m})$ reverse-phase column at, mobile phase $\mathrm{CH}_{3} \mathrm{CN}$ and $5 \mathrm{mM} \mathrm{NH} \mathrm{CH} \mathrm{CO}$ buffer was used at a flow rate of $0.250 \mathrm{~mL} / \mathrm{min} .2^{4} \mu \mathrm{L}^{3}$ of extracts were injected with the elution of solvent started with $5 \% \mathrm{CH}_{3} \mathrm{CN}(\mathrm{A})$ and increased up to $80 \%$ over 24 minutes. A linear gradient was applied for CGs elution from 5-30\% A (6 min), 30-60\% A (12 min), 60-60\% A (20 min), 60-80\% A (24 min) and moves to the initial chromatographic condition of $80-5 \%$ A $(30 \mathrm{~min})$. Electrospray ionization (ESI) source operated in the $\mathrm{ES} \pm$ ion mode and $\mathrm{N}_{2}$ used as nebulizing and drying gas at flow rates of 50 and $650 \mathrm{~L} / \mathrm{h}$, respectively. ESI source parameters were capillary voltage at $3.5 \mathrm{kV}$ and cone voltage at $30 \mathrm{~V}$. Source and desolvation temperature was set at 120 and $350^{\circ} \mathrm{C}$, respectively. The data were acquired scan range of m/z 150- 1500 Th. Argon was used as collision gas and collision-cell energy ramping from $30-5 \mathrm{eV}$ leads to achieving $5-30 \%$ relative intensity of each precursor ion. MassLynx (vs. 4.1) software was used for data acquisition and processing. Similarly, accurate mass measurement of CGs was recorded on Thermo Orbitrap Velos pro hybrid Mass Spectrometer (USA). It was equipped with an Accela UHPLC system with an ESI source. Thermo Accucore Cl $8(150 \times 2.1 \mathrm{~mm}, 2.6 \mu \mathrm{m})$ reverse-phase column was used with the same linear-gradient mobile phase as above.

\section{Data Analysis}

All the experiments were performed in triplicate and results were calculated as mean $\pm \mathrm{SE}$. The data from comparison of metabolite accumulation in the IVP vs. ACP was statistically analyzed by analysis of variance performed using statistical software SPSS 15.0 for Windows (SPSS Inc., Chicago, IL, USA). Statistically significant differences between the groups were compared using one-way analysis of variance (ANOVA) at $\mathrm{p}=0.05$.

\section{RESULT}

\section{Optimization of Germination Media}

Considering the overall germination percentage of zygotic embryos, MS medium was found to be the best, followed by WPM, SHM and B5 media. ${ }^{1 / 4} \mathrm{MS}$ medium with $15 \mathrm{gm} / 1$ sucrose showed the best result with $\sim 97 \%$ germination rate, followed by $\sim 93 \%$ germination in the full as well as $1 / 2$ strength of WPM also with $15 \mathrm{gm} / \mathrm{l}$ sucrose. Full-strength MS medium with the $15 \mathrm{gm} / 1$ sucrose concentration also showed a good germination percentage, i.e., $\sim 90 \%$. Whereas $\sim 87 \%$ germination was observed on sucrose-free full-strength MS medium, 1/2 MS medium with $15 \mathrm{gm} / \mathrm{l}$ sucrose, 1/4 MS medium with $30 \mathrm{gm} / \mathrm{l}$ sucrose, full-strength WPM medium with $30 \mathrm{gm} / \mathrm{l}$ sucrose and 1/4 WPM medium with $15 \mathrm{gm} / 1$ sucrose. $1 / 2$ SHM and the fullstrength B5 with $15 \mathrm{gm} / 1$ sucrose and the sucrose-free 1/4 WPM media also showed more than $80 \%$ germination rate (Table 1 ). On the other hand, the maximum germination percentage of mature wild seeds under in vitro conditions was noticed only $30 \%$ (data not shown).

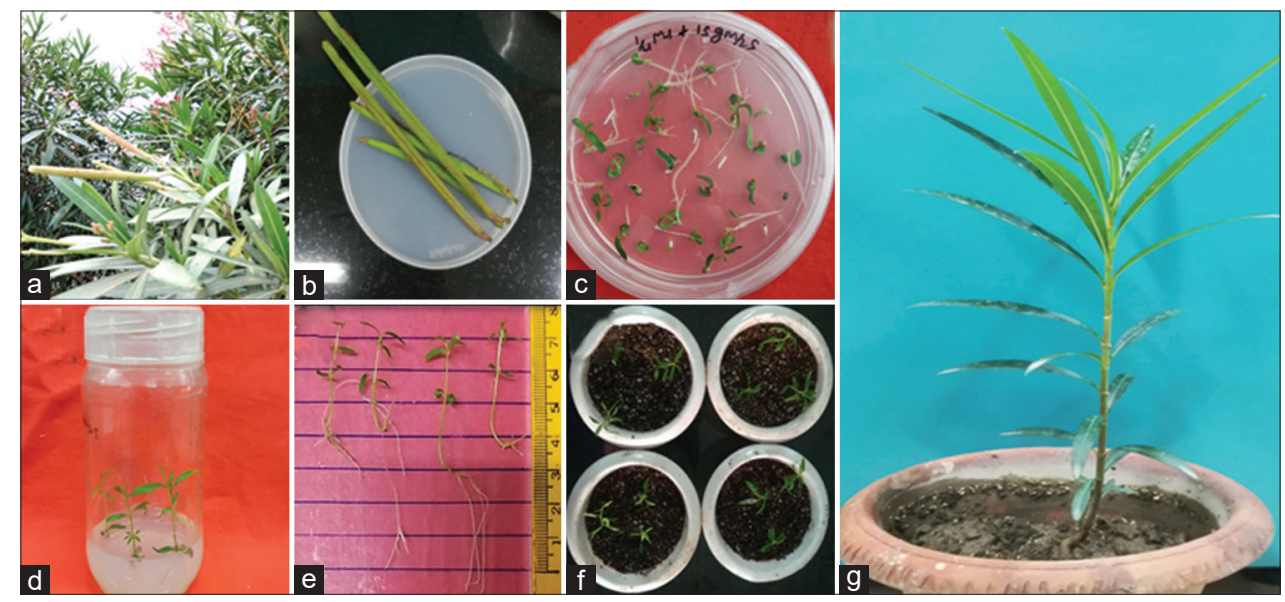

Figure 1: Standardization of zygotic embryo culture from N.oleander (a) fruiting twigs (b) immature fruits (c) germination of zygotic embryos (d) in vitro plantlets in culture bottles (e) measurement of in vitro plantlets (f) in vitro plantlets under controlled environmental conditions (g) complete acclimatized plant 


\section{Optimization of growth media}

Vegetative growth of IVP was found to be controlled by all the three factors like type and strength of culture media as well as the concentration of sucrose. These factors played their role either independently or in combination. Sucrose supplementation was supposed to exhibit a significant impact on seedling growth. Under sucrose-free conditions, the vegetative growth of IVP in all tested media was suppressed and ranged between 1.3 to $3.8 \mathrm{~cm}$. However, when sucrose was added to the media in 15 and $30 \mathrm{gm} / \mathrm{l}$ concentration, IVP height was increased, ranging between 2.4 to $4.8 \mathrm{~cm}$ depending upon the media type and strength used. Further, when the role of the media type and their strength on the growth of IVP was studied, it was observed that $1 / 2$ B5 medium with 30 and $15 \mathrm{gm} / \mathrm{l}$ sucrose was the best, followed by $1 / 4$ MS medium with $30 \mathrm{gm} / \mathrm{l}$ sucrose. The IVP height in these media was 4.8, 4.7 and $4.5 \mathrm{~cm}$, respectively (Table 2 ).

\section{Identification and Quantification of CGs in IVP}

Out of around 72 CGs reported from various parts of this plant globally, 09 were identified as per our previously established method (Figure 2, Table 3) (Tripathi et al., 2013; Pandey et al., 2016; Singh et al., 2021) using MS/MS fragmentation

Table 1: Germination percentage of zygotic embryos of $N$. oleander on different germination media

\begin{tabular}{lccc}
\hline Germination Media & \multicolumn{3}{c}{$\%$ Germination (mean \pm SE) (1 week) $\mathrm{n}=60$} \\
\cline { 2 - 4 } (salt strength gm/l) & $30 \mathrm{gm} / \mathrm{l}$ Sucrose & $15 \mathrm{gm} / \mathrm{l}$ Sucrose & $0 \mathrm{gm} / \mathrm{l}$ Sucrose \\
\hline MS & $80.00 \pm 11.54$ & $90.00 \pm 5.77$ & $86.66 \pm 6.66$ \\
l/2 MS & $66.60 \pm 6.6$ & $86.66 \pm 6.66$ & $73.33 \pm 6.66$ \\
l/4 MS & $86.60 \pm 3.33$ & $96.66 \pm 3.33$ & $56.66 \pm 3.33$ \\
WPM & $86.60 \pm 6.66$ & $93.33 \pm 6.66$ & $60.00 \pm 11.54$ \\
l/2 WPM & $76.60 \pm 8.81$ & $93.33 \pm 6.66$ & $73.33 \pm 11.54$ \\
l/4 WPM & $53.30 \pm 6.66$ & $86.66 \pm 6.66$ & $80.00 \pm 11.54$ \\
SHM & $66.60 \pm 13.33$ & $70.00 \pm 9.99$ & $63.33 \pm 12.01$ \\
l/2 SHM & $66.60 \pm 6.66$ & $83.33 \pm 3.33$ & $66.66 \pm 6.66$ \\
l/4 SHM & $73.33 \pm 6.66$ & $76.66 \pm 3.33$ & $70.00 \pm 9.99$ \\
B5 & $30.00 \pm 5.77$ & $80.00 \pm 9.99$ & $73.33 \pm 6.66$ \\
l/2 B5 & $50.00 \pm 5.70$ & $76.33 \pm 8.81$ & $76.66 \pm 8.81$ \\
l/4 B5 & $70.00 \pm 5.70$ & $73.33 \pm 6.66$ & $66.66 \pm 3.33$ \\
\hline
\end{tabular}

Table 2: Growth of in vitro N. oleander plantlets on various growth media

\begin{tabular}{lccc}
\hline $\begin{array}{l}\text { Growth Media } \\
\text { (salt strength } \mathrm{gm} / \mathrm{l})\end{array}$ & \multicolumn{3}{c}{ Growth cm (mean \pm SE) (1 month) $\mathrm{n}=60$} \\
\cline { 2 - 4 } & $30 \mathrm{gm} / \mathrm{l}$ Sucrose & $15 \mathrm{gm} / \mathrm{l}$ Sucrose & $\begin{array}{c}0 \mathrm{gm} / \mathrm{l} \\
\text { Sucrose }\end{array}$ \\
\hline MS & $2.9 \pm 0.36$ & $3.1 \pm 0.15$ & $1.3 \pm 0.17$ \\
l/2 MS & $3.6 \pm 0.44$ & $4.2 \pm 0.14$ & $1.9 \pm 0.30$ \\
l/4 MS & $4.5 \pm 0.15$ & $4.2 \pm 0.15$ & $3.4 \pm 0.46$ \\
WPM & $2.9 \pm 0.08$ & $3.1 \pm 0.08$ & $2.3 \pm 0.20$ \\
1/2 WPM & $4.0 \pm 0.48$ & $2.5 \pm 0.09$ & $2.6 \pm 0.19$ \\
1/4 WPM & $3.2 \pm 0.45$ & $3.3 \pm 0.49$ & $2.9 \pm 0.23$ \\
SHM & $3.9 \pm 0.13$ & $2.5 \pm 0.13$ & $2.1 \pm 0.16$ \\
1/2 SHM & $4.3 \pm 0.33$ & $3.8 \pm 0.31$ & $2.7 \pm 0.17$ \\
1/4 SHM & $3.8 \pm 0.30$ & $2.8 \pm 0.52$ & $3.8 \pm 0.26$ \\
B5 & $2.4 \pm 0.24$ & $4.0 \pm 0.61$ & $2.6 \pm 0.23$ \\
1/2 B5 & $4.7 \pm 0.75$ & $4.8 \pm 0.26$ & $2.8 \pm 0.55$ \\
1/4 B5 & $3.5 \pm 0.29$ & $3.7 \pm 0.63$ & $3.1 \pm 0.05$ \\
\hline
\end{tabular}

pattern, accurate mass measurement (ESI-HRMS) and earlier published CGs structures from this plant (Supplementary Information, Figure S1-S9). The mass spectrometry data of detected CGs in IVP and ACP have been shown in Table 3. From the quantitative analysis, it was observed that the accumulation of all the CGs was found to be varied significantly in IVP depending on growth media, salt strength and sucrose concentration. Full-strength SHM medium with $15 \mathrm{gm} / \mathrm{l}$ sucrose was found optimum for the accumulation of three CGs viz. CG 840a (1.61 mg/gm DW), CG 842 $(2.28 \mathrm{mg} / \mathrm{gm} \mathrm{DW})$ and CG $840 \mathrm{~b}(1.89 \mathrm{mg} / \mathrm{gm} \mathrm{DW})$. The same medium with $30 \mathrm{gm} / \mathrm{l}$ sucrose and sucrose free fullstrength WPM medium also favored the accumulation of CG 840 a $(1.51 \mathrm{mg} / \mathrm{gm}$ DW) and CG 840b (1.84 mg/gm DW) respectively. Sucrose free full-strength SHM medium showed the best effect on the accumulation of CG 901 $(0.34 \mathrm{mg} / \mathrm{gm} \mathrm{DW})$ in comparison to others, which was followed by the full-strength WPM with $15 \mathrm{gm} / \mathrm{l}$ sucrose and sucrose-free conditions ( 0.29 and $0.28 \mathrm{mg} / \mathrm{gm}$ DW). Maximum accumulation of odoroside A $(32.71 \mathrm{mg} / \mathrm{gm} \mathrm{DW})$ was found in $1 / 2$ SHM media with $30 \mathrm{gm} / 1$ sucrose, whereas its accumulation (32.39 mg/gm DW) was also comparable in sucrose-free $1 / 4$ SHM medium. MS medium, with its different strength and sucrose concentrations, favored the accumulation of 03 CGs. CG 738 was accumulated at maximum level $(2.89 \mathrm{mg} / \mathrm{gm}$ DW) in sucrose-free, full-strength MS medium. Optimum accumulation of oleandrin was noticed on $1 / 2$ MS medium with $15 \mathrm{gm} / \mathrm{l}$ sucrose $(0.52 \mathrm{mg} / \mathrm{gm}$ DW) and sucrose-free $(0.51 \mathrm{mg} / \mathrm{gm} \mathrm{DW})$ conditions. Odoroside $\mathrm{H}$ was found to be accumulated in maximum quantity $(4.69 \mathrm{mg} / \mathrm{gm} \mathrm{DW})$ on sucrose-free $1 / 4$ MS medium, whereas $1 / 2$ MS medium either with sucrose-free condition or with $15 \mathrm{gm} / \mathrm{l}$ sucrose also favors its accumulation (4.67 mg/gm DW, $4.57 \mathrm{mg} / \mathrm{gm} \mathrm{DW})$. Full-strength sucrose-free B5 medium was found to favor the accumulation of only CG 754 (1.6 mg/gm DW) (Figure 3).

\section{CGs Quantification in ACP and Their Comparison with IVP}

All the 09 identified CGs could also be detected in ACP, which were quantified and compared with their maximum accumulation within IVP. It was revealed that ACP accumulated a lower concentration of almost all the CGs. A significant decrease of odoroside A was observed from $32.71 \mathrm{mg} / \mathrm{gm}$ DW to $11.71 \mathrm{mg} / \mathrm{gm}$ DW, whereas the concentration of odoroside $\mathrm{H}$ was almost reduced to half from $4.69 \mathrm{mg} / \mathrm{gm}$ DW to $2.12 \mathrm{mg} / \mathrm{gm}$ DW in ACP. Oleandrin accumulation was also found to be diminished to almost nil, i.e., from 0.52 to $0.01 \mathrm{mg} / \mathrm{gm}$ DW. Other CGs viz. CG 840a, CG 754 and CG 842 showed a significant reduction in their quantities from 1.89 , 1.62 and $2.27 \mathrm{mg} / \mathrm{gm}$ DW in IVP to $0.97,0.43$ and $1.83 \mathrm{mg} / \mathrm{gm}$ DW respectively in ACP. CG 901, which was accumulated in low quantity i.e., $0.29 \mathrm{mg} / \mathrm{gm} \mathrm{DW}$ in IVP, was further reduced to $0.15 \mathrm{mg} / \mathrm{gm}$ DW in ACP. CG 738 was also slightly reduced from 2.88 to $2.30 \mathrm{mg} / \mathrm{gm}$ DW. CG $840 \mathrm{~b}$ is the only CG, which was found to be accumulated in higher quantity within ACP (2.93 mg/gm DW) with compare to IVP (1.61 mg/gm DW) (Figure 4). 


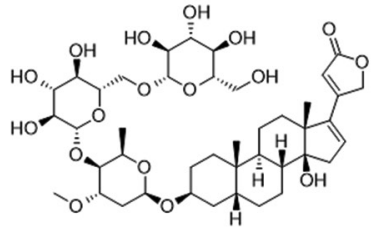

a
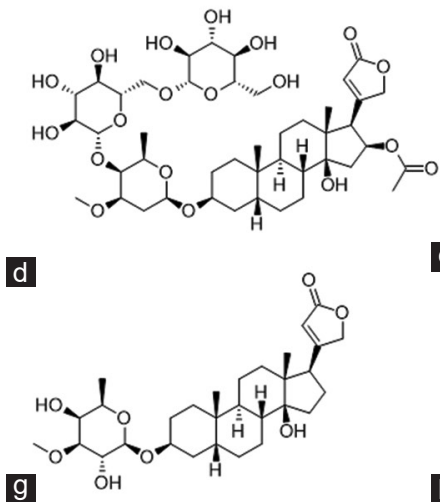

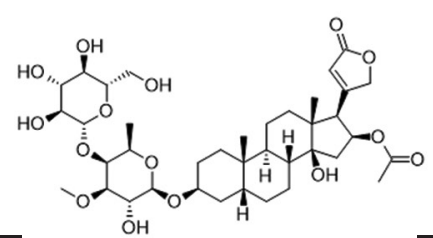

b

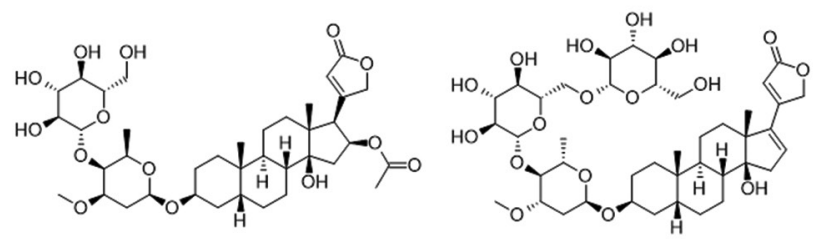

e

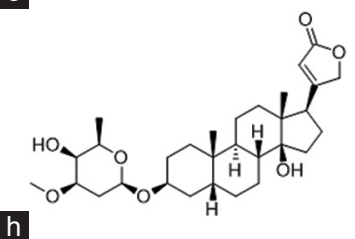

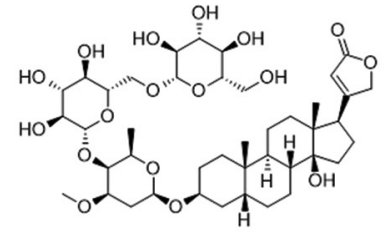

f

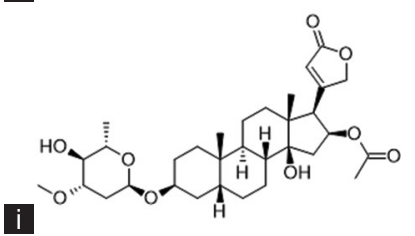

Figure 2: Identified structures of cardiac glycoside in in vitro grown and acclimatized plantlets (a) CG840a (b) CG754 (c) CG842 (d) CG901 (e) CG738 (f) CG840b (g) CG534 (h) CG518 (i) CG576

Table 3: Identification of CGs in in vitro grown and acclimatized plantlets

\begin{tabular}{|c|c|c|c|c|c|c|c|}
\hline S. No. & RT & Analyte code & Compound name & ESI-HRMS & MF & MW & $\begin{array}{l}\text { CGs product-ions in ESI+ ion mode } \\
(\mathrm{m} / \mathrm{z} \% \text { relative intensity })\end{array}$ \\
\hline 1. & 2.28 & CG 840a & $\begin{array}{l}\triangle^{16} \text { Anhydrogitoxigenin- } \beta \text { - } \\
\text { D-sar- } \beta \text {-D-glu- } \beta \text {-D-glu }\end{array}$ & {$\left[\mathrm{M}+\mathrm{NH}_{4}\right]^{+} 858.4476$} & $\mathrm{C}_{42} \mathrm{H}_{64} \mathrm{O}_{17}$ & 840 & $\begin{array}{c}373(35), 325(32), 275(29), 163(25) \\
145(47), 113(100), 95(31)\end{array}$ \\
\hline 2. & 2.85 & CG 754 & $\begin{array}{l}\text { Oleandrigenin- } \beta \text {-D-digi- } \\
\beta \text {-D-glu }\end{array}$ & {$\left[\mathrm{M}+\mathrm{NH}_{4}\right]^{+} 772.4100$} & $\mathrm{C}_{38} \mathrm{H}_{58} \mathrm{O}_{15}$ & 754 & $\begin{array}{c}593(15), 433(100), 373(15), 355(12), \\
323(4), 161(5)\end{array}$ \\
\hline 3. & 3.40 & CG 842 & $\begin{array}{l}\text { Digitoxigenin- } \beta \text {-D-dig- } \beta \text { - } \\
\text { D-glu- } \beta \text {-D-glu }\end{array}$ & {$\left[\mathrm{M}+\mathrm{NH}_{4}\right]^{+} 860.4614$} & $\mathrm{C}_{42} \mathrm{H}_{66} \mathrm{O}_{17}$ & 842 & $\begin{array}{c}631(13), 437(11), 375(31), 325(32) \\
275(29), 163(20), 145(35), 113(100), \\
95(34)\end{array}$ \\
\hline 4. & 3.55 & CG 901 & $\begin{array}{l}\text { Oleandrigenin- } \beta \text {-D-dig- } \beta- \\
\text { D-glu- } \beta \text {-D-glu }\end{array}$ & {$\left[\mathrm{M}+\mathrm{NH}_{4}\right]^{+} 918.4688$} & $\mathrm{C}_{44} \mathrm{H}_{72} \mathrm{O}_{19}$ & 901 & $\begin{array}{c}433(95), 373(5), 355(9), 325(12), \\
275(28), 163(20), 145(22), 113(100), \\
95(25)\end{array}$ \\
\hline 5. & 4.23 & CG 738 & $\begin{array}{l}\text { Oleandrigenin- } \beta \text {-D-dig- } \\
\beta \text {-D-glu }\end{array}$ & {$\left[\mathrm{M}+\mathrm{NH}_{4}\right]^{+} 756.4166$} & $\mathrm{C}_{38} \mathrm{H}_{58} \mathrm{O}_{14}$ & 738 & $433(68), 373(18), 145(62), 113(100)$ \\
\hline 6. & 4.75 & CG 840b & $\begin{array}{l}\triangle^{16} \text { Anhydrogitoxigenin- } \beta \text { - } \\
\text { D-ole- } \beta \text {-D-glu- } \beta \text { - } D \text {-glu }\end{array}$ & {$\left[\mathrm{M}+\mathrm{NH}_{4}\right]^{+} 858.4474$} & $\mathrm{C}_{42} \mathrm{H}_{64} \mathrm{O}_{17}$ & 840 & $\begin{array}{c}373(19), 325(13), 275(17), 163(23) \\
145(40), 113(100), 95(24)\end{array}$ \\
\hline 7. & 5.40 & CG 534 & $\begin{array}{l}\text { Digitoxigenin- } \beta \text {-D-digi } \\
\text { (Odoroside H) }\end{array}$ & $\begin{array}{l}{[\mathrm{M}+\mathrm{H}]^{+}} \\
535.3266\end{array}$ & $\mathrm{C}_{30} \mathrm{H}_{46} \mathrm{O}_{8}$ & 534 & $\begin{array}{c}375(31), 357(22), 339(24), 87(100) \\
161(8)\end{array}$ \\
\hline 8. & 8.40 & CG 518 & $\begin{array}{l}\text { Digitoxigenin- } \beta \text {-D-dig } \\
\text { (Odoroside A) }\end{array}$ & $\begin{array}{l}{[\mathrm{M}+\mathrm{H}]^{+}} \\
519.3321\end{array}$ & $\mathrm{C}_{30} \mathrm{H}_{47} \mathrm{O}_{7}$ & 518 & $\begin{array}{c}375(73), 357(8), 339(18), 145(95) \\
113(100)\end{array}$ \\
\hline 9. & 9.10 & CG 576 & $\begin{array}{l}\text { Oleandrigenin-L-ole } \\
\text { (Oleandrin) }\end{array}$ & $\begin{array}{l}{[\mathrm{M}+\mathrm{H}]^{+}} \\
577.3375\end{array}$ & $\mathrm{C}_{32} \mathrm{H}_{49} \mathrm{O}_{9}$ & 576 & $\begin{array}{c}517(22), 433(34), 373(85), 355(36), \\
337(10), 145(62), 113(100)\end{array}$ \\
\hline
\end{tabular}

$\mathrm{RT}=$ Retention time, $\mathrm{MF}=$ molecular formula, $\mathrm{MW}=$ molecular weight, and $\mathrm{m} / \mathrm{z}=$ mass to charge ratio

\section{DISCUSSION}

In the present study, the germination percentage of $N$. oleander zygotic embryos was found much higher than the wild mature seeds in the culture medium, which might be due to the presence of various inhibitors in the seed coat (Kaveri \& Rao, 2015). However, some other direct (Karrunakaran \& Shri, 2010; Hatzilazarou et al., 2019) and indirect in vitro micropropagation techniques are reported from this plant (DH Paper, 1989; Santos et al., 1994; Vila et al., 2010) yet no ZEC and CGs profiling of acclimatized and in vitro raised plants found to be reported in our knowledge. ZEC depends on many factors including the source of carbon and other nutrients used, which helps in the germination, survival and growth of the delicate
IVP. In the present study, we achieved maximum germination percentage of $\mathrm{N}$. oleander zygotic embryos at a lower sucrose concentration $(15 \mathrm{gm} / \mathrm{l})$, whereas the higher $(30 \mathrm{gm} / \mathrm{l})$ and the sucrose-free conditions did less favor. A similar observation was reported in Schisandra chinensis, where lower concentrations of sucrose $(2 \%)$ in the medium increased the germination percentage (Chen et al., 2010). On the contrary, in some other cases like Givotia rottleriformis and Boswellia serrata a higher germination percentage of zygotic embryos was noticed at $30 \mathrm{gm} / 1$ sucrose than its lower concentrations $(7.5 \& 15 \mathrm{gm} /$ ) (Rambabu et al., 2006; Ghorpade et al., 2010). Such types of contradictory results indicate that sucrose concentration for ZEC is very much species-specific. Sucrose in the media serves as a primary carbon source and most importantly, it controls the 


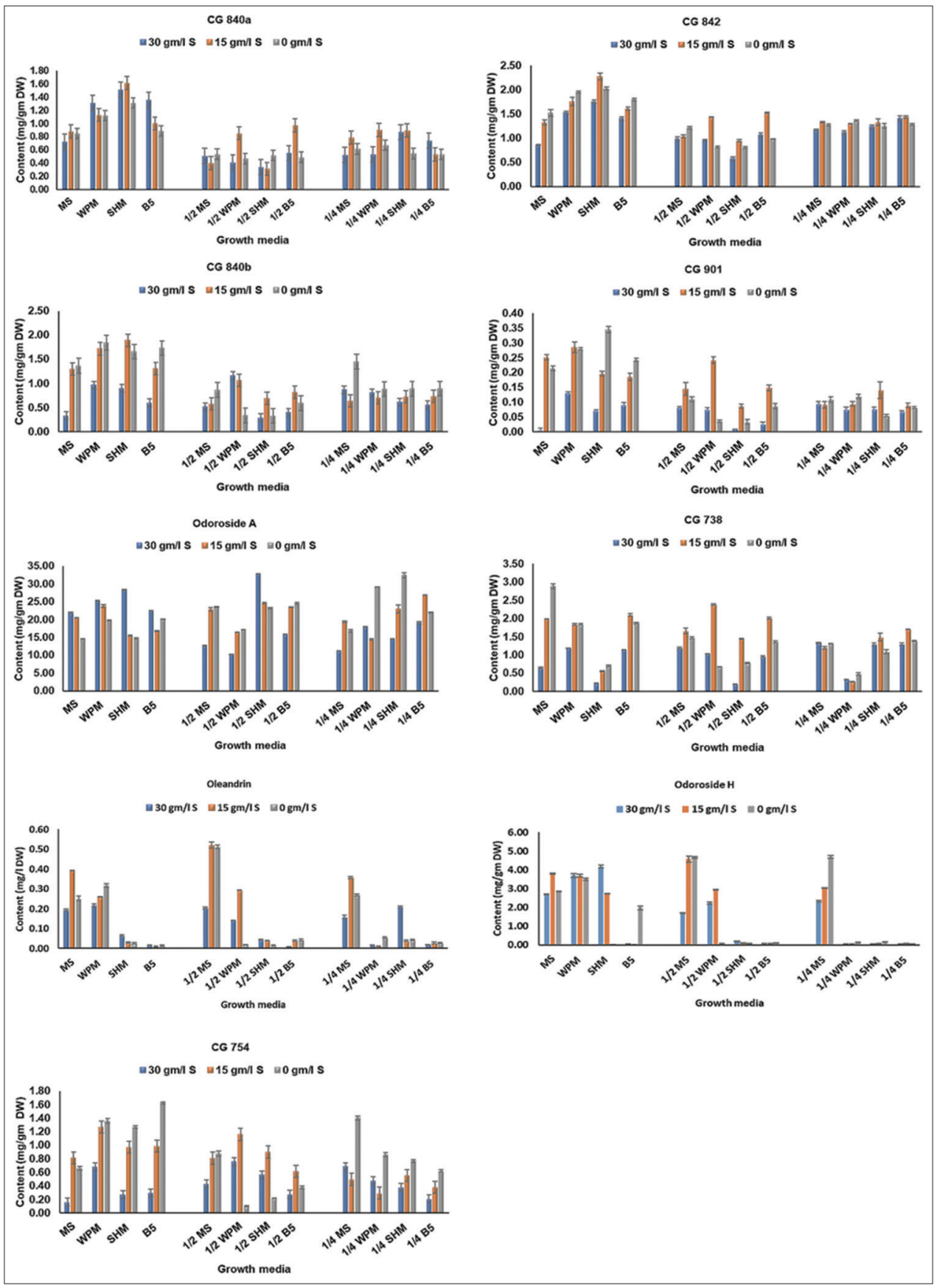

Figure 3. CGs accumulation in different types and strength of culture media with various sucrose concentrations

osmotic balance (Bridgen, 1994; Raghavan, 1977, 2003). In our study, both lower $(15 \mathrm{gm} / \mathrm{l})$ and higher $(30 \mathrm{gm} / \mathrm{l})$ concentrations of sucrose were found to support the growth and proliferation of IVP. Such positive effects of sucrose on plantlets growth under in vitro conditions are well known and have already been documented earlier (Mills, 2009; Thorpe \& Yeung, 2011). Along with sucrose, the source and concentration of nitrogen in the media are also responsible for the germination of zygotic embryos. So, it becomes necessary to optimize the media type and their strength. In our experiment, we observed that the best medium for germination of zygotic embryo of N. oleander was $1 / 4 \mathrm{MS}$, which was immediately followed by the full strength and $1 / 4$ WPM media. In all these media, the common source of nitrogen is ammonium nitrate and its concentration ranges from 200 to $400 \mathrm{mg} /$, which is far less than the full MS and other media. This observation is supported by an earlier work, where the reduced concentration of ammonium nitrate as a primary source of nitrogen favored the zygotic embryo culture of Datura sp. (MATSUBARA, 1964; Umbeck \& Norstog, 1979; George et al., 2008). For the growth of IVP, B5 media was found to be the best at both 30 and $15 \mathrm{gm} / \mathrm{l}$ sucrose levels. A similar observation was also reported during in vitro seedling establishment of Jatropha curcas (Warakagoda \& Subasinghe, 2009). Regarding CGs content within in vitro grown plantlets of $\mathrm{N}$. oleander, 05 CGs were found to be accumulated at maximum level in the plantlets, grown on SHM medium. 


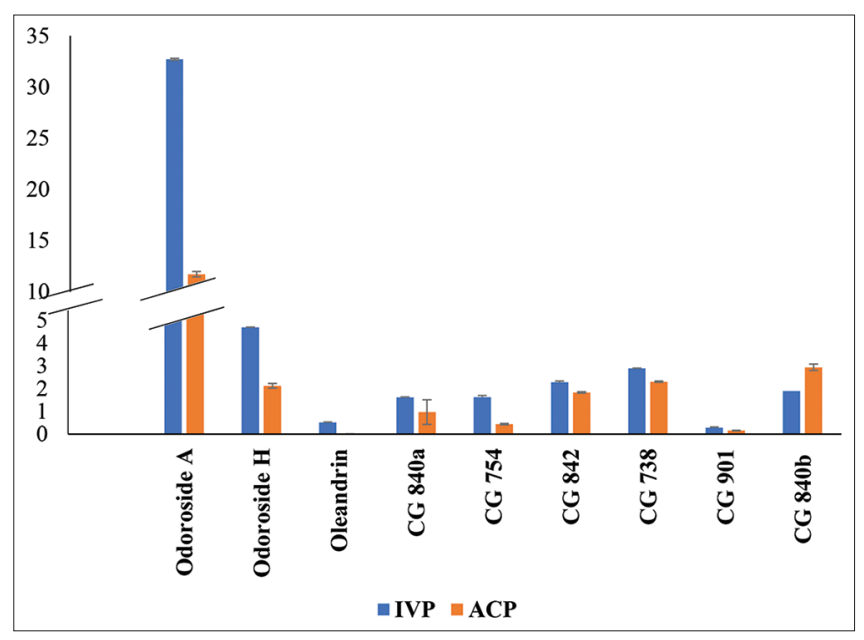

Figure 4. Comparative analysis of CGs accumulation in in vitro (IVP) vs acclimatized plants (ACP)

The plantlets on the rest of the media also accumulated these CGs albeit at lower concentrations. SHM medium supports the higher accumulation of maximum CGs, possibly due to its low nitrogen and high phosphate concentrations. One earlier worker also made a similar observation during enhanced oleandrin biosynthesis from the same plant (Ibrahim et al., 2009b). Following the SHM, MS medium was found to elicit the accumulation of 03 other CGs, which is similar to an earlier report on higher accumulation of periplocin in Periploca sepium on MS medium (Zhang et al., 2011). Further, when the quantity of CGs accumulated within IVP and ACP were compared, a prominent distinction was observed and the IVP were found far superior. This observation strongly suggests that IVP are the better option for CGs biosynthesis and enrichment-related research as compared to naturally grown plants.

\section{CONCLUSION}

The complete study was planned in two parts. In the first part, in vitro multiplication protocol of $\mathrm{N}$. oleander through ZEC was standardized and plantlets were acclimatized under natural conditions. In the second part, accumulated CGs in both in vitro grown and ACP were identified and quantified through LC-MS. Optimum germination medium was observed as $1 / 4$ MS with $15 \mathrm{gm} / \mathrm{sucrose}$, whereas the best growth medium was standardized as $1 / 2 \mathrm{~B} 5$ with both $30 \mathrm{gm} / \mathrm{l}$ and $15 \mathrm{gm} / 1$ sucrose. A total of 09 CGs could be identified and quantified in both in vitro as well as ACP, of which 08 were found maximally accumulated within IVP. On the other hand, ACP were found to favor the maximum accumulation of only 01 CG. From the overall experiments, it can be concluded that the ZEC is a quick and efficient method for micropropagation of N. oleander, whereas for CGs accumulation in vitro grown plantlets are the better option.

\section{ACKNOWLEDGMENT}

Renu Nimoriya (RN) acknowledges University Grant Commission (UGC), New Delhi; Yatendra Singh (YS), Sumit Kumar Singh (SKS), Pankaj Singh (PS) \& Carol Janis Bilung
(CJB) are grateful to Council of Scientific and Industrial Research (CSIR) and Amar Jeet (AJ) is thankful to Department of Biotechnology (DBT) under Government of India, for their fellowships. SKS and CJB are grateful to AcSIR for providing academic facilities in the research work. We sincerely thank SAIF\&R, CSIR-CDRI, for the analytical facilities. Authors also acknowledge Department of Science \& Technology (Project EMR/2016/006674; GAP0257), and Department of Biotechnology (project BT/BIO-CARe/01/421/2011-12; GAP0180), Government of India for financial support. Paper bears communication number 10332.

\section{REFERENCES}

Bai, L., Zhao, M., Toki, A., Hasegawa, T., Sakai, J. ichi, Yang, X. yang, Bai, Y., Ogura, H., Mitsui, T., Kataoka, T., Ando, M., Hirose, K., \& Ando, M. (2011). Polar cardenolide monoglycosides from stems and twigs of Nerium oleander and their biological activities. Journal of Wood Science, 57(1), 47-55. https://doi.org/10.1007/s10086-010-1138-x

Bai, Y., Zhao, M., Bai, L., Hasegawa, R., Sakai, J. ichi, Hasegawa, T., Mitsui, T., Ogura, H., Kataoka, T., Hirose, K., \& Ando, M. (2011). The biological activities of cardenolide triglycosides from stems, twigs, and leaves of Nerium oleander. Journal of Wood Science, 57(1), 56-65. https://doi.org/10.1007/s10086-010-1132-3

Bridgen, M. P. (1994a). A review of plant embryo culture. HortScience, 29(11), 1243-1246. https://doi.org/10.21273/HORTSCI.29.11.1243

Cao, Y. L., Zhang, M. H., Lu, Y. F., Li, C. Y., Tang, J. S., \& Jiang, M. M. (2018). Cardenolides from the leaves of Nerium oleander. Fitoterapia, 127 , 293-300. https://doi.org/10.1016/j.fitote.2018.03.004

Chen, A. H., Yang, J. L., Niu, Y. da, Yang, C. P., Liu, G. F., Yu, C. Y., \& Li, C. H. (2010). High-frequency somatic embryogenesis from germinated zygotic embryos of Schisandra chinensis and evaluation of the effects of medium strength, sucrose, GA3, and BA on somatic embryo development. Plant Cell, Tissue and Organ Culture, 102(3). https:// doi.org/10.1007/s11240-010-9740-6

Colapietro, A., Yang, P., Rossetti, A., Mancini, A., Vitale, F., Martellucci, S., Conway, T. L., Chakraborty, S., Marampon, F., \& Mattei, V. (2020). The Botanical Drug PBI-05204, a Supercritical $\mathrm{CO}_{2}$ Extract of Nerium Oleander, Inhibits Growth of Human Glioblastoma, Reduces Akt/ mTOR Activities, and Modulates GSC Cell-Renewal Properties. Frontiers in Pharmacology, 11, 1438. https://doi.org/10.3389/ fphar.2020.552428

Dogar, N. A., Shahid, H., Shaukat, H. U., Khan, M. A., \& Saleem, F (2020). Phytochemical Evaluation and Anti-Inflammatory Activity of Ethanolic Extract of Calotropis procera Leaves. RADS Journal of Biological Research \& Applied Sciences, 11(1). https://doi.org/10.37962/jbas.v11i1.243

Ekalu, A., Ayo, R. G.-O., Habila, J. D., \& Hamisu, I. (2019). A mini-review on the phytochemistry and biological activities of selected Apocynaceae plants. Journal of Herbmed Pharmacology, 8(4). https://doi. org/10.15171/jhp.2019.39

Gamborg, O. L., Miller, R. A., \& Ojima, K. (1968). Nutrient requirements of suspension cultures of soybean root cells. Experimental cell research, 50(1), 151-158. https://doi.org/10.1016/00144827(68)90403-5

George, E. F., Hall, M. A., \& Klerk, G. J. de. (2008). Plant propagation by tissue culture $3^{\text {rd }}$ edition. Springer, Dordrecht, The Netherlands, 1, 501. https:// doi.org/10.1007/978-1-4020-5005-3

Ghorpade, R. P., Chopra, A., \& Nikam, T. D. (2010). In vitro zygotic embryo germination and propagation of an endangered Boswellia serrata Roxb., a source of boswellic acid. Physiology and Molecular Biology of Plants, 16(2), 159-165. https://doi.org/10.1007/s12298-010-0017-7

Grosser, J. W., \& Collins, G. B. (1984). Isolation and culture of Trifolium rubens protoplasts with whole plant regeneration. Plant Science Letters, 37(1-2). https://doi.org/10.1016/0304-4211(84)90220-7

Hagimori, M., Matsumoto, T., \& Obi, Y. (1982). Studies on the Production of Digitalis Cardenolides by Plant Tissue Culture. Plant Physiology. https://doi.org/10.1104/pp.69.3.653

Hanada, R., Abe, F., \& Yamauchi, T. (1992). Steroid glycosides from the roots of Nerium odorum. Phytochemistry, 31(9), 3183-3187. https:// doi.org/10.1016/0031-9422(92)83471-A 
Haslam, T. M., \& Yeung, E. C. (2011). Zygotic embryo culture: an overview. Methods in Molecular Biology (Clifton, N.J.), 710(3), 3-15. https://doi. org/10.1007/978-1-61737-988-8 1

Hatzilazarou, S., Kostas, S., \& Economou, A. S. (2019). Plant regeneration of Nerium oleander $\mathrm{L}$. from alginate-encapsulated shoot explants after short-term cold storage. Journal of Horticultural Science and Biotechnology, 94(4), 441-447. https://doi.org/10.1080/14620316.2 018.1542283

Ibrahim, A., Khalifa, S., Khafagi, I., Youssef, D., Khan, I., \& Mesbah, M. (2009). Enhancement of oleandrin production in suspension cultures of Nerium oleander by combined optimization of medium composition and substrate feeding. Plant Biosystems - An International Journal Dealing with All Aspects of Plant Biology, 143(1), 97-103. https://doi. org/10.1080/11263500802633683

Isah, T., Umar, S., Mujib, A., Sharma, M. P., Rajasekharan, P. E., Zafar, N., \& Frukh, A. (2018). Secondary metabolism of pharmaceuticals in the plant in vitro cultures: strategies, approaches, and limitations to achieving higher yield. In Plant Cell, Tissue and Organ Culture. https://doi.org/10.1007/s11240-017-1332-2

Soundararajan, T., Karrunakaran, C. M., \& Shri, P. (2010). Micropropagation of Nerium Oleander through the immature Pods. Journal of Agricultura/ Science, 2(2), 181. https://doi.org/10.5539/jas.v2n2p181

Kaveri, S., \& Rao, S. (2015). In vitro seed germination and Embryo Culture in Nothapodytes foetida (Wight) Sleumer. International Letters of Natural Sciences, 48. https://doi.org/10.18052/www.scipress.com/ ILNS.48.23

Liu, R., Su, B., Huang, F., Ru, M., Zhang, H., Qin, Z., Li, Y., \& Zhu, K. (2019). Identification and analysis of cardiac glycosides in Loranthaceae parasites Taxillus chinensis (DC.) Danser and Scurrula parasitica Linn. and their host Nerium indicum Mill. Journal of Pharmaceutical and Biomedical Analysis, 174, 450-459. https://doi.org/10.1016/j. jpba.2019.05.071

Matsubara, S. (1964). Effect of nitrogen compounds on the growth of isolated young embryos of Datura. Botanical Magazine Tokyo, 77, 253-259. https://doi.org/10.15281/JPLANTRES1887.77.253

Matsui, H., \& Schwartz, A. (1968). Mechanism of cardiac glycoside inhibition of the $(\mathrm{Na}+-\mathrm{K}+)$-dependent ATPase from cardiac tissue. BBA - Enzymology, 151(3). https://doi.org/10.1016/00052744(68)90013-2

McCown, B. H. (1981). Woody Plant Medium (WPM)-a mineral nutrient formulation for microculture for woody plant species. HortScience, 16, 453.

Mekhail, T., Kaur, H., Ganapathi, R., Budd, G. T., Elson, P., \& Bukowski, R. M. (2006). Phase 1 trial of Anvirzel ${ }^{\mathrm{TM}}$ in patients with refractory solid tumors. Investigational New Drugs, 24(5), 423-427. https://doi. org/10.1007/s10637-006-7772-x

Menger, L., Vacchelli, E., Kepp, O., Eggermont, A., Tartour, E., Zitvogel, L., Kroemer, G., Galluzzi, L., Menger, L., Vacchelli, E., Adjemian, S., Martins, I., Ma, Y., Sukkurwala, A. Q., Michaud, M., Galluzzi, L., Zitvogel, L., Kroemer, G., Bai, Y.,... Guchelaar, H. J. (2013). Anticancer activity of cardiac glycosides: At the frontier between cell-autonomous and immunological effects. Oncolmmunology, 1(2), 1640-1642. https://doi.org/10.4161/onci.23082

Mills, D. (2009). Effect of sucrose application, minerals, and irradiance on the in vitro growth of Cistus incanus seedlings and plantlets. Biologia Plantarum, 53(3). https://doi.org/10.1007/s10535-009-0080-5

Murashige, T., \& Skoog, F. (1962). A revised medium for rapid growth and bio assays with tobacco tissue cultures. Physiologia Plantarum. https://doi.org/10.1111/j.1399-3054.1962.tb08052.x

Newman, R. A., Yang, P., Pawlus, A. D., \& Block, K. I. (2008). Cardiac glycosides as novel cancer therapeutic agents. Molecular Interventions, 8(1). https://doi.org/10.1124/mi.8.1.8

Pandey, A., Swarnkar, V., Pandey, T., Srivastava, P., Kanojiya, S., Mishra, D. K., \& Tripathi, V. (2016). Transcriptome and metabolite analysis reveal candidate genes of the cardiac glycoside biosynthetic pathway from Calotropis procera. Scientific Reports, 6(1), 1-14. https://doi. org/10.1038/srep34464

Paper D.H., G. F. (1989). Tissue cultures of Nerium oleander growth rate, components and biotransformation of the cardenolide aglycone digitoxigenine. Planta Medica, 55, 223. https://doi. org/10.1055/s-2006-961968

Plante, K., Plante, J., Fernandez, D., Mirchandani, D., Bopp, N., Aguilar, P., Sastry, K. J., Newman, R., \& Weaver, S. (2020). Prophylactic and therapeutic inhibition of in vitro SARS-CoV-2 replication by oleandrin. BioRxiv: The Preprint Server for Biology. https://doi.

\section{org/10.1101/2020.07.15.203489}

Raghavan, V. (1977). Applied aspects of embryo culture. Reinert, J., and Bajaj, YPS, (Eds. Applied and Fundamental Aspects of Plant Cell Tissue Culture, Berlin-Heidelberg-New York: Springer-Verlag, 375-397.

Raghavan, V. (2003). One hundred years of zygotic embryo culture investigations. In Vitro Cellular \& Developmental Biology - Plant, 39(5), 437-442. https://doi.org/10.1079/IVP2003436

Rambabu, M., Upender, M., Ujjwala, D., Ugandhar, T., Praveen, M., \& Swamy, N. R. (2006). In vitro zygotic embryo culture of an endangered forest tree Givotia rottleriformis and factors affecting its germination and seedling growth. In Vitro Cellular and Developmental Biology - Plant, 42(5), 418-421. https://doi.org/10.1079/IVP2006804

Ramming, D. W. (2019). The use of embryo culture in fruit breeding. HortScience, 25 (4), 393-398. https://doi.org/10.21273/hortsci.25.4.393

Reddy, D., Kumavath, R., Barh, D., Azevedo, V., \& Ghosh, P. (2020). Anticancer and antiviral properties of cardiac glycosides: A review to explore the mechanism of actions. Molecules, 25(16), 3596. https:// doi.org/10.3390/molecules25163596

Santos, I., Guimarães, I., \& Salema, R. (1994). Somatic embryogenesis and plant regeneration of Nerium oleander. Plant Cell, Tissue and Organ Culture, 37(1), 83-86. https://doi.org/10.1007/BF00048122

Schenk, R. U., \& Hildebrandt, A. C. (1972). Medium and techniques for induction and growth of monocotyledonous and dicotyledonous plant cell cultures. Canadian Journal of Botany, 50, 199-204. https:// doi.org/10.1139/b72-026

Siddiqui, B. S., Khatoon, N., Begum, S., Farooq, A. D., Qamar, K., Bhatti, H. A., \& Ali, S. K. (2012). Flavonoid and cardenolide glycosides and a pentacyclic triterpene from the leaves of Nerium oleander and evaluation of cytotoxicity. Phytochemistry, 77, 238-244. https://doi. org/10.1016/j.phytochem.2012.01.001

Singh, P., Singh, Y., Jeet, A., Nimoriya, R., Kanojiya, S., Tripathi, V., \& Mishra, D. (2019). Standardization of enrichment protocols for some medicinally important cardenolides within in vitro grown Calotropis gigantea plantlets. Pharmacognosy Magazine, 15(61), 264. https:// doi.org/10.4103/pm.pm_507_18

Singh, Y., Nimoriya, R., Rawat, P., Mishra, D. K., \& Kanojiya, S. (2021). Structural analysis of diastereomeric cardiac glycosides and their genins using ultraperformance Liquid Chromatography-Tandem Mass Spectrometry. Journal of the American Society for Mass Spectrometry, 32(5), 1205-1214 https://doi.org/10.1021/jasms.1c00017

Thorpe, T. A., \& Yeung, E. C. (2011). Plant Embryo Culture: Methods and Protocols. Methods in Molecular Biology.

Tiwari, G., Rathour, B. K., Mishra, S. K., \& Sagar, R. (2020). New CNS depressant cardenolide glycoside from the roots of Nerium oleander. Results in Chemistry, 2, 100035. https://doi.org/10.1016/j. rechem.2020.100035

Tripathi, P. K., Awasthi, S., Kanojiya, S., Tripathi, V., \& Mishra, D. K. (2013). Callus culture and in vitro biosynthesis of cardiac glycosides from Calotropis gigantea (L.) Ait. In Vitro Cellular and Developmental Biology - Plant, 49(4). https://doi.org/10.1007/s11627-012-9481-9

Umbeck, P. F., \& Norstog, K. (1979). Effects of abscisic acid and ammonium ion on morphogenesis of cultured barley embryos. Bulletin of the Torrey Botanical Club, 110-116. https://doi.org/10.2307/2484285

Vila, I., Sales, E., Ollero, J., Muñoz-Bertomeu, J., Segura, J., \& Arrillaga, I. (2010). Micropropagation of Oleander (Nerium oleander L.). HortScience, 45(1), 98-102. https://doi.org/10.21273/ HORTSCI.45.1.98

Wang, X., Plomley, J. B., Newman, R. A., \& Cisneros, A. (2000). LC/MS/ MS analyses of an oleander extract for cancer treatment. Analytical Chemistry, 72(15), 3547-3552. https://doi.org/10.1021/ac991425a

Warakagoda, P. S., \& Subasinghe, S. (2009). In vitro culture establishment and shoot proliferation of Jatropha curcas L., Tropical Agricultural Research and Extension, 12(2).

Zhang, J., Gao, W. Y., Wang, J., \& Li, X. L. (2011). Effects of explant types and media salt strength on growth and secondary metabolite accumulation in adventitious roots of Periploca sepium Bunge. Acta Physiologiae Plantarum, 33(6), 2447-2452. https://doi.org/10.1007/ s11738-011-0785-x

Zhao, M., Bai, L., Toki, A., Hasegawa, R., Sakai, J. I., Hasegawa, T., Ogura, H., Kataoka, T., Bai, Y., Ando, M., Hirose, K., \& Ando, M. (2011). The structure of a new cardenolide diglycoside and the biological activities of eleven cardenolide diglycosides from Nerium oleander. Chemical and Pharmaceutical Bulletin, 59(3), 371-377. https://doi. org/10.1248/cpb.59.371 


\section{SUPPLEMENTARY FILE}

\section{Supporting Information}

\section{CG840a}

RT: 2.28; $\Delta^{16}$ Anhydrogitoxigenin- $\beta$-D-sar- $\beta$-D-glu- $\beta$-D-glu (Liu et al., 2019); observed ions ESI+ $m / z 841[\mathrm{M}+\mathrm{H}]^{+}, 858\left[\mathrm{M}+\mathrm{NH}_{4}\right]^{+}$, ESI- $m / z 839[\mathrm{M}-\mathrm{H}]^{-}, 899\left[\mathrm{M}+\mathrm{CH}_{3} \mathrm{COO}\right]^{-}, \mathrm{M} . \mathrm{W} .840 \mathrm{Da}$.

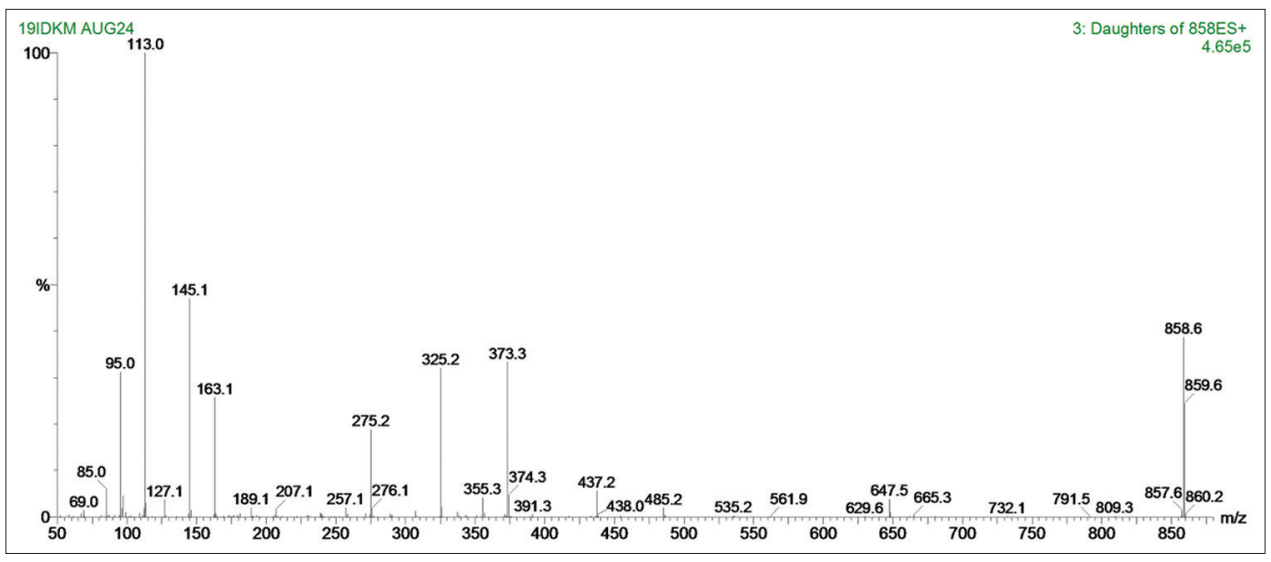

Figure S1. MS/MS spectra of $\Delta^{16}$ Anhydrogitoxigenin- $\beta$-D-sar- $\beta$-D-glu- $\beta$-D-glu.

\section{CG754}

RT: 2.85; Oleandrigenin- $\beta$-D-digi- $\beta$-D-glu(Zhao et al., 2011); observed ions ESI+ m/z $755[\mathrm{M}+\mathrm{H}]^{+}, 772\left[\mathrm{M}+\mathrm{NH}_{4}\right]^{+}$, ESI- $m / z 753[\mathrm{M}-\mathrm{H}] ;, 813\left[\mathrm{M}+\mathrm{CH}_{3} \mathrm{COO}\right]^{-}$, M.W. 754 Da.

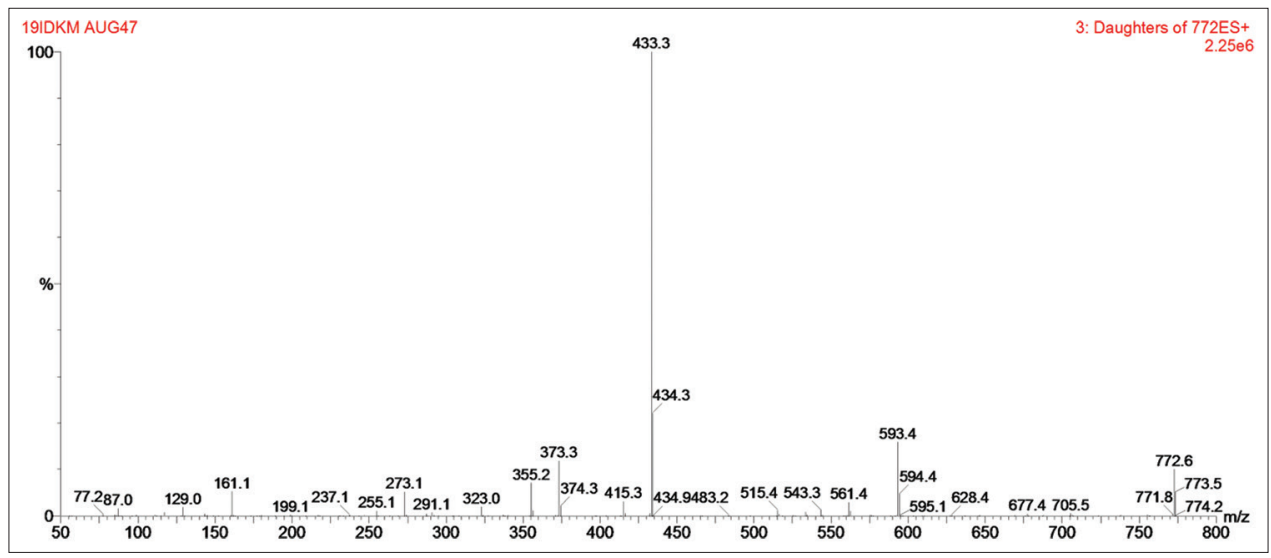

Figure S2. MS/MS spectra of Oleandrigenin- $\beta$-D-digi- $\beta$-D-glu.

\section{CG842}

RT: 3.40; Digitoxigenin- $\beta$-D-dig- $\beta$-D-glu- $\beta$-D-glu (Odoroside A gentiobioside)(Y. Bai et al., 2011); observed ions ESI+ $m / z$ $843[\mathrm{M}+\mathrm{H}]^{+}, 860\left[\mathrm{M}+\mathrm{NH}_{4}\right]^{+}$, ESI- m/z $841[\mathrm{M}-\mathrm{H}]^{-}, 901\left[\mathrm{M}+\mathrm{CH}_{3} \mathrm{COO}\right]^{;}, \mathrm{M} . \mathrm{W} .842 \mathrm{Da}$. 


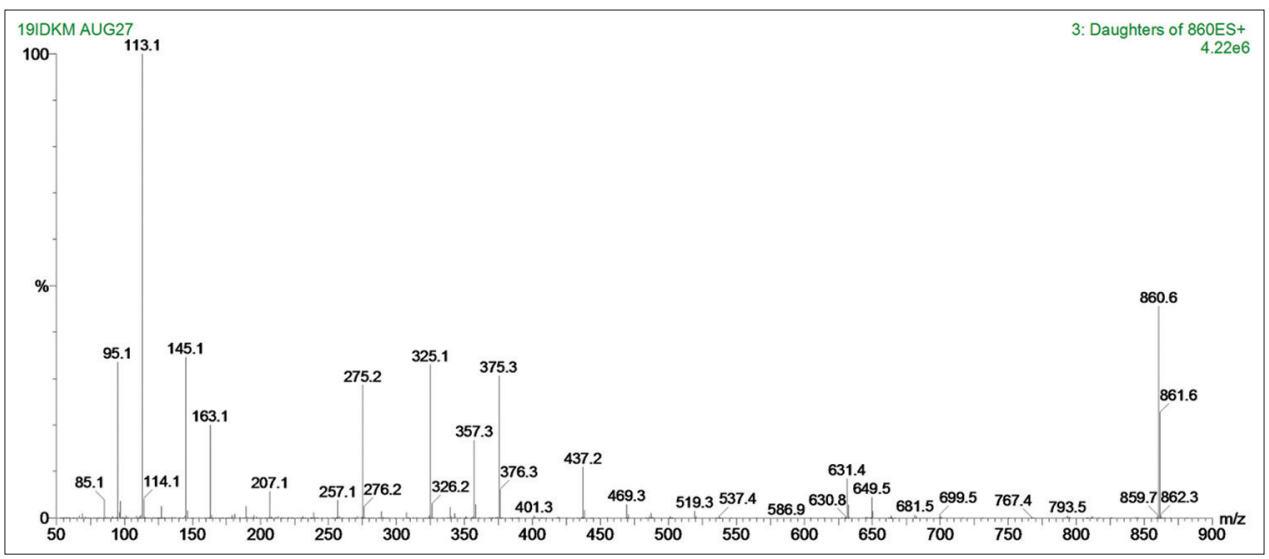

Figure S3. MS/MS spectra of Digitoxigenin- $\beta$-D-dig- $\beta$-D-glu- $\beta$-D-glu (Odoroside A gentiobioside).

\section{CG901}

RT: 3.55; Oleandrigenin- $\beta$-D-dig- $\beta$-D-glu- $\beta$-D-glu(Hanada et al., 1992), observed ions ESI+ m/z $902[\mathrm{M}+\mathrm{H}]^{+}, 919\left[\mathrm{M}+\mathrm{NH}_{4}\right]^{+}$, ESI- $m / z 900[\mathrm{M}-\mathrm{H}]^{-}, 960\left[\mathrm{M}+\mathrm{CH}_{3} \mathrm{COO}\right]^{-}, \mathrm{M} . \mathrm{W} .901 \mathrm{Da}$.

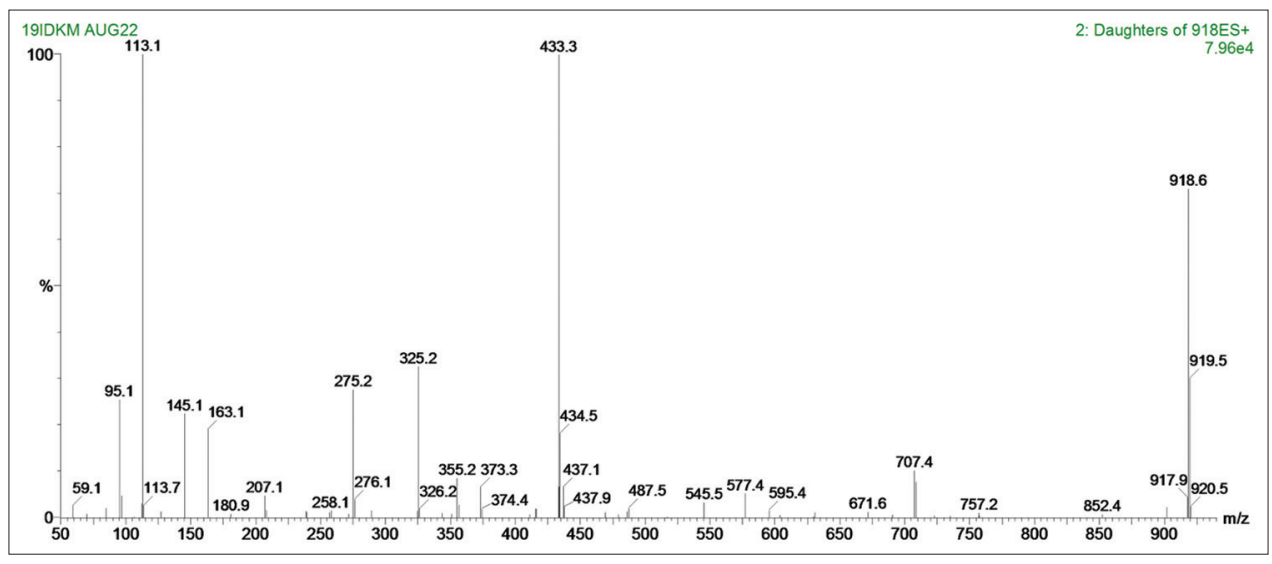

Figure S4. MS/MS spectra of Oleandrigenin- $\beta$-D-dig- $\beta$-D-glu- $\beta$-D-glu.

\section{CG738}

RT: 4.23; Oleandrigenin- $\beta$-D-dig- $\beta$-D-glu (Hanada et al., 1992), observed ions ESI+ m/z $739[\mathrm{M}+\mathrm{H}]^{+}, 756[\mathrm{M}+\mathrm{NH}]^{+}$, ESI- $\mathrm{m} / z$ $737[\mathrm{M}-\mathrm{H}]^{-}, 797\left[\mathrm{M}+\mathrm{CH}_{3} \mathrm{COO}\right]^{-}$, M.W. 738 Da.

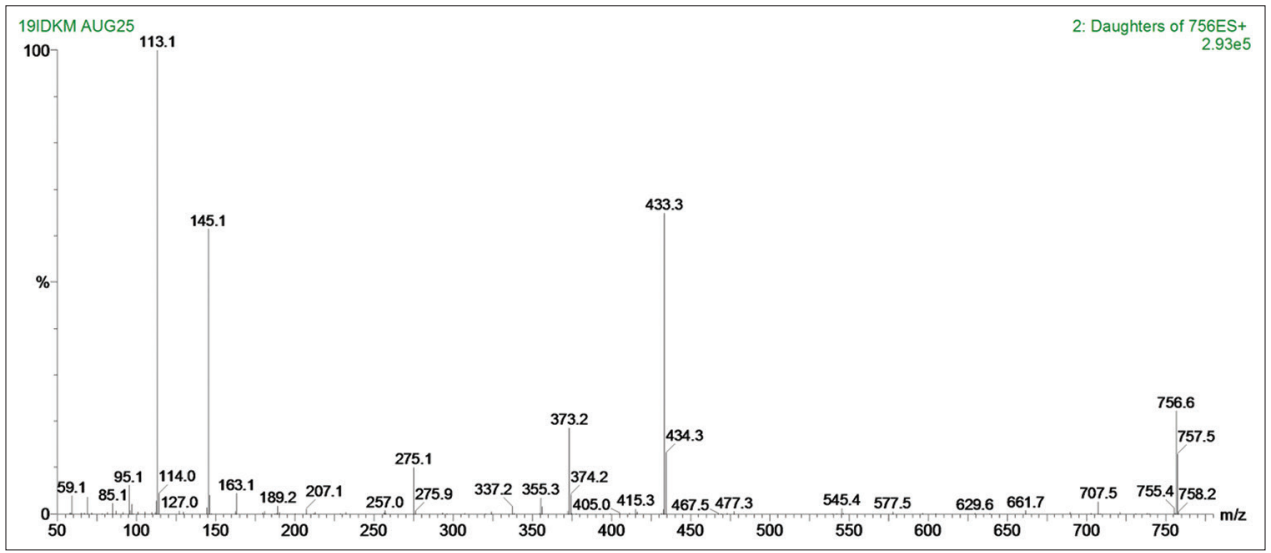

Figure S5. MS/MS spectra of Oleandrigenin- $\beta$-D-dig- $\beta$-D-glu. 


\section{CG840b}

RT: 4.75; $\Delta$ l6Anhydrogitoxigenin- $\beta$-D-ole- $\beta$-D-glu- $\beta$-D-glu(Y. Singh et al., 2021); observed ions ESI+ m/z $841[\mathrm{M}+\mathrm{H}]^{+}$, $858\left[\mathrm{M}+\mathrm{NH}_{4}\right]^{+}$, ESI- $\mathrm{m} / z 839[\mathrm{M}-\mathrm{H}]^{;}, 899\left[\mathrm{M}+\mathrm{CH}_{3} \mathrm{COO}\right]^{;}$, M.W. 840 Da.

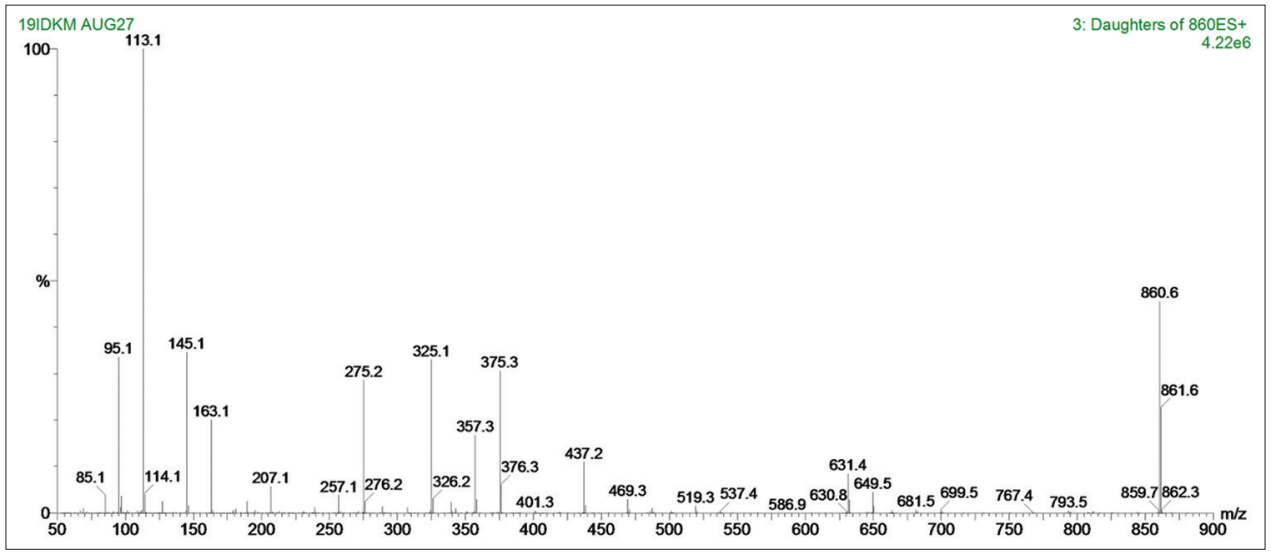

Figure S6. MS/MS spectra of $\Delta^{16}$ Anhydrogitoxigenin- $\beta$-D-ole- $\beta$-D-glu- $\beta$-D-glu.

\section{CG534}

RT: 5.40; Digitoxigenin- $\beta$-D-digi (Odoroside H)(L. Bai et al., 2011); observed ions ESI+ m/z $535[\mathrm{M}+\mathrm{H}]^{+}, 552\left[\mathrm{M}+\mathrm{NH}_{4}\right]^{+}$, $557[\mathrm{M}+\mathrm{Na}]^{+}$, ESI- m/z $533[\mathrm{M}-\mathrm{H}]^{-}, 593\left[\mathrm{M}+\mathrm{CH}_{3} \mathrm{COO}\right] ;$, M.W. 534 Da.

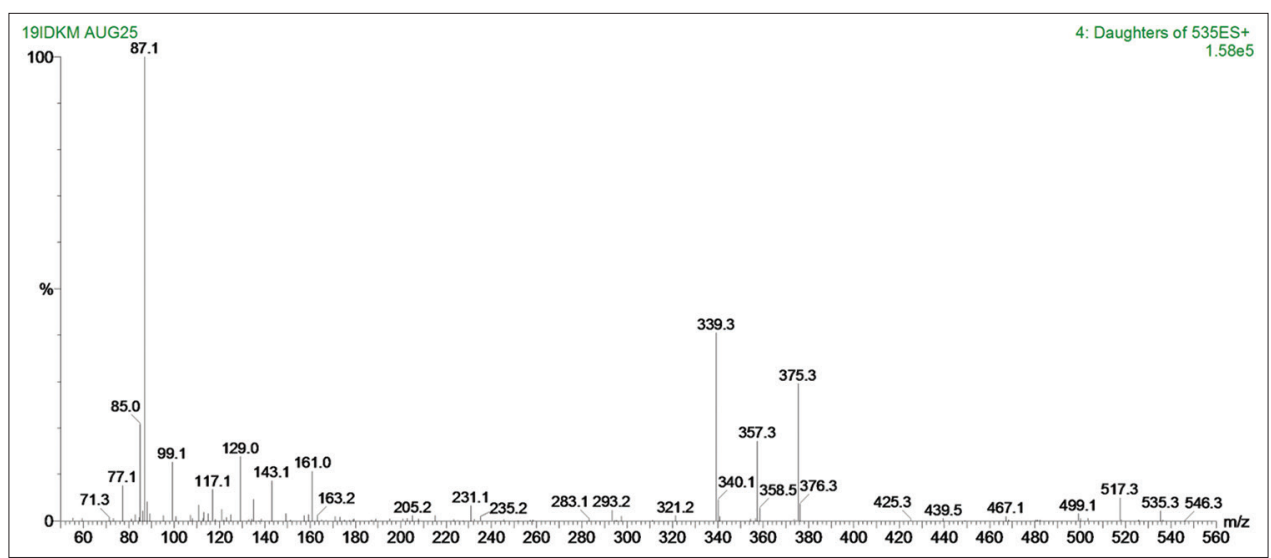

Figure S7. MS/MS spectra of Digitoxigenin- $\beta$-D-digi (Odoroside H).

\section{CG518}

RT: 8.40; Digitoxigenin- $\beta$-D-dig (Odoroside A) (Cao et al., 2018); observed ions ESI+ $m / z 519[\mathrm{M}+\mathrm{H}]^{+}, \quad 536\left[\mathrm{M}^{+} \mathrm{NH}_{4}\right]^{+}$, $541[\mathrm{M}+\mathrm{Na}]^{+}$, ESI- m/z $517[\mathrm{M}-\mathrm{H}]^{-}, 577\left[\mathrm{M}+\mathrm{CH}_{3} \mathrm{COO}\right]^{-}, \mathrm{M} . \mathrm{W} .518 \mathrm{Da}$.

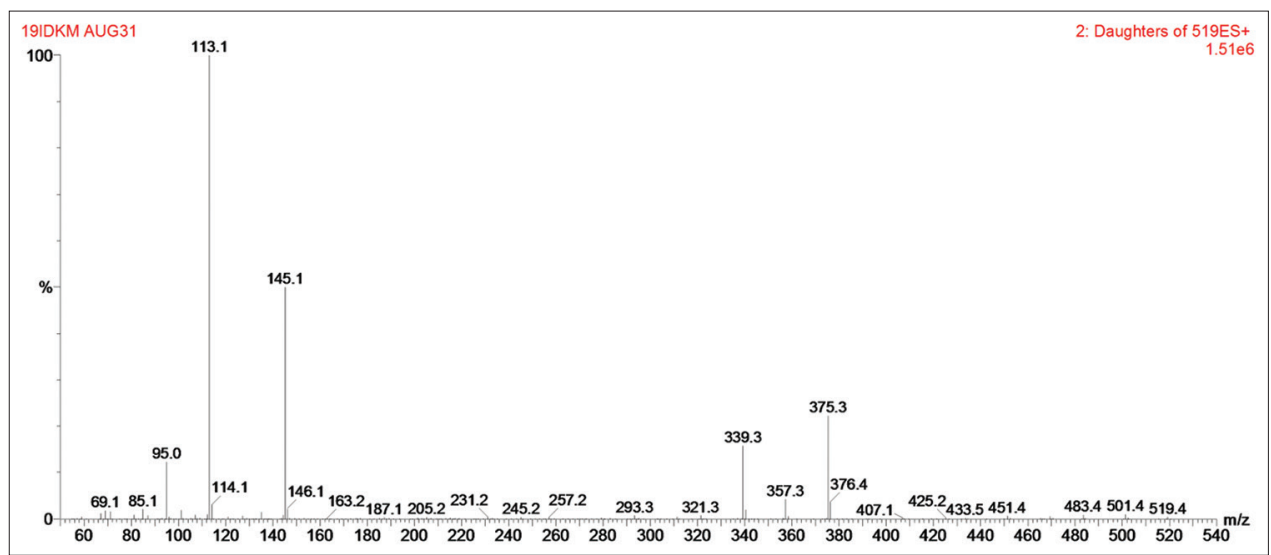

Figure S8. MS/MS spectra of Digitoxigenin- $\beta$-D-dig (Odoroside A). 


\section{CG576}

RT: 9.10; Oleandrigenin-L-ole (Oleandrin)(Siddiqui et al., 2012); observed ions ESI+ m/z $577[\mathrm{M}+\mathrm{H}]^{+}, 594\left[\mathrm{M}+\mathrm{NH}_{4}\right]^{+}$, $599[\mathrm{M}+\mathrm{Na}]^{+}$, ESI- m/z $575[\mathrm{M}-\mathrm{H}]^{-}, 635\left[\mathrm{M}+\mathrm{CH}_{3} \mathrm{COO}\right]^{-}$, M.W. 576 Da.

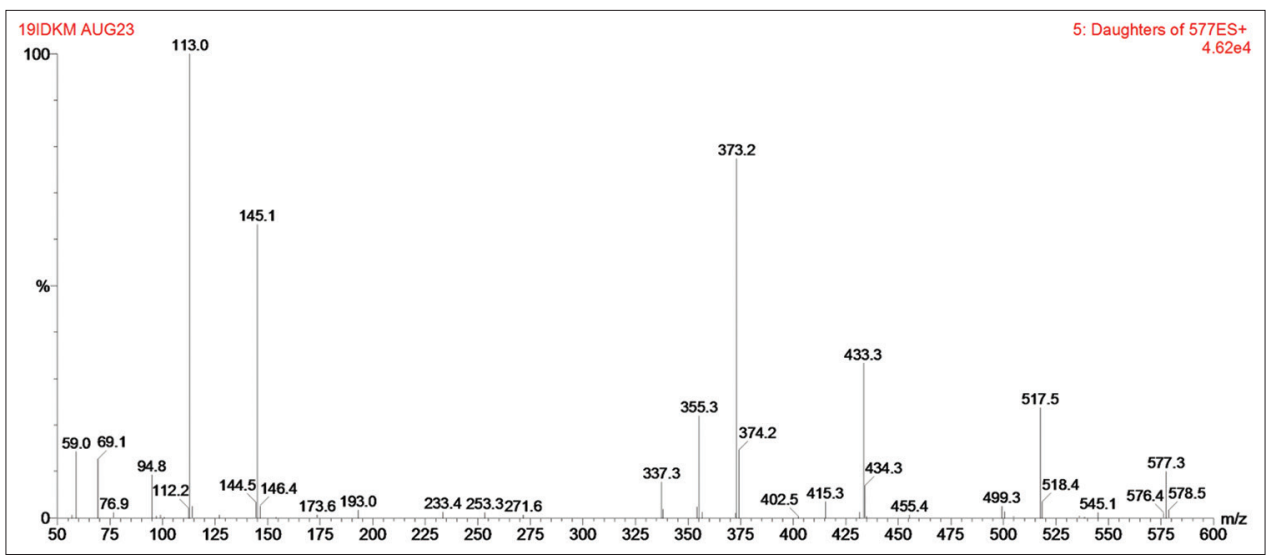

Figure S9. MS/MS spectra of Oleandrigenin-L-ole (Oleandrin). 